\title{
Dilemmas about Quality of Life in Older People
}

\author{
J. Gabura (Jan Gabura), M. Mojtova (Martina Mojtova)
}

Constantine The Philosopher University in Nitra, Nitra, Slovakia.

\section{E-mail address:}

jgabura@sercom.sk

\section{Reprint address:}

Jan Gabura

Constantine The Philosopher University in Nitra

Tr. A. Hlinku 1

94901

Nitra

Slovakia

Source: Clinical Social Work and Health Intervention

Volume: 11

Issue: 3

Pages: 7 - 11

Cited references: 12

\section{Reviewers:}

Mageswaari Rajoo

Bangkok, Thailand

Michael Costello

University of Scranton School of Education, USA

\section{Keywords:}

Quality of Life. Older People.

\section{Publisher:}

International Society of Applied Preventive Medicine i-gap

CSWHI 2020; $11(3)$ : 7 - 11; DOI: 10.22359/cswhi_11_3_01 C Clinical Social Work and Health Intervention

\section{Abstract:}

Currently, the topic of quality of life, hence quality of life in older people is relatively frequent in theory, research, projects and practice. An important dilemma in this area is the absence of a specific and straightforward definition of quality of life, which makes the concept and its use in the practice of helping professions difficult to fulfill. Another dilemma of the topic is the effort to reduce the concept of quality of life to individual domains which may affect certain aspects of quality of life in a broader context, but quality of life cannot be reduced to them. In the paper, we tried to map certain aspects of quality of life in older people which could allow workers in helping professions to comprehensively identify and effectively exploit the broad aspects of domains and factors in reciprocal intercon- 
nectedness. The topic of quality of life in older people should be part of the vision of social organizations in the future, their organizational culture, training of workers and part of their daily cooperation with clients. The condition for an organization to focus on quality of life of its clients is to create optimal conditions of quality of life for its workers. The two aspects of quality of life form the communicating vessels bringing about the synergic effect.

Recently, the concept of quality has been intensively penetrating the theory and practice of helping scientific disciplines. The concept is often used in the contexts of quality of performance; quality of services; quality of cooperation; quality of relationships; in the area of research as its qualitative form. One of the paradoxes in this area, however, is that very often quality is unilaterally assessed based on quantitative indicators, such as frequency, duration, repeatability, etc., which usually do not indicate quality. For example, an older person may have a relatively frequent contact with professional staff, but the frequency of their contacts does not say anything about the quality of the service or relationship, because even frequent inappropriate contact with a professional can be traumatizing or harming for the client. Even the currently implemented systems of quality of social services related to cooperation with older people have not prevented similar problems.

Methodological problems are identified already in the definition and content of the concept of quality of life. The term quality of life is currently very fashionable and is one the most common phrases in the area of helping professions. Schalock (2004) states that from 1985 to 2004 the phrase quality of life was used in the titles of 21,000 publications and articles around the world, even though there is no generally accepted definition of the concept of quality of life. In content, the concept of quality of life is rather vague, and difficult to be clearly grasped and defined. According to Cummins (in: Rapley, 2003), quality of life is one of the least consistently used concepts in social sciences. The term quality of life is often used so carelessly that one must think a lot of the presented meaning of the expression. Also, Wolfensberger (in: Rapley, 2003) perceives the situation with the use of the concept of quality of life similarly. He argues that the concept of quality of life sounds excellent in the speeches, political declarations, and talks at scientific conferences, but in research or practice, the concept becomes a very uncertain and difficult-to-beclearly-grasped instrument. Furthermore, the vagueness and ambiguity of the concept arise from the fact that the concept of quality of life has both the lay and professional contexts; it is examined by various disciplines of science (sociology, psychology, medicine, social work, economics, social policy, etc.) from quite different angles. The differences can also be perceived when looking at the concept of quality of life from the aspect of the purpose of its use. The term can be used to map the current or past situations; we can use it in the process of planning a change, in an evaluation system, and when setting up and evaluating the standards of certain conditions or activities. The problem stimulating vagueness is also the confusion of the concept of quality of life with the concepts of standard of living, needs, health status, satisfaction, or happiness. For these reasons, the concept of quality of life requires an accurate definition and a consequent use in the context of the definition adopted. Some authors, for example Keih (2001, in: Scottish Executive, 2005), argue that the concept of quality of life cannot be accurately defined, and therefore scientists only examine certain aspects of quality of life, without seeking an explicit definition of quality of life as a complex phenomenon. A similar situation is also in Slovakia. The concept of quality of life is freely used in theory, the field of social policy, legislation, practice; it is the topic of major projects without its exact definition. It is usually defined only generally or reduced to some of its aspects.

The concept of quality of life, mainly in its subjective component, significantly correlates with satisfaction with various areas in its individual domains of life. From several definitions of life satisfaction, we incline to the definition by Fahrenberg et al. (2000, in: Džuka, 2004), ac- 
cording to which life satisfaction is an individual assessment of past and present conditions of life and life expectations. Life satisfaction is most often influenced by aspirations; social comparisons; values. The risk of such an approach to satisfaction is that clients can become easily satisfied with poor quality.

Svehlikova \& Heretik (2008) specified three basic approaches related to quality of life that can be used in fulfilling and exploring quality of life in older people. The psychological approach works with the subjectively experienced life wellbeing of the older person, and the satisfaction of the older person with his own life, inner wellbeing. The approach has a cognitive dimension that is related to the rational assessment of life by the older person and an emotional dimension that is dominated by the experiencing of quality of life by the older person. The sociological approach focuses on the attributes of social success of the older person: social security; property; social status; level of education; family status; subjective life feelings in relation to other people. Its important part is standard of living. The third approach that forms part of quality of life in the older person is the medical approach. In the medical approach, the focus is on the health impact on quality of life in the older person; accessibility and quality of health care; the level of health insurance and the possibility of its use. Social Work with older people should be an effective combination of the elements of all three approaches which should be used effectively in social services for older people by professionals and social organizations.

Increasing quality of life has become a part of the visions and objectives of helping professions. In relation to our topic, experts are interested in quality of life in older people in various contexts of their lives, and as we are active in the social field, we will also seek the relationship between quality of life and social needs of older people. In social services for older people, quality of life can serve as an element of increasing susceptibility in professional interventions; as a philosophy of accessibility of service providers for older people which focuses the attention of professionals mainly on the individual perspective of the receiver of services as a benchmark for the assessment of professional interventions of workers (Schalock, 2004). If we want to deal with quality of life in older people, we should start from the identified typologies of quality of life structures. Scottish Executive (2005) presents three types of definitions of quality of life:

- General global definitions, mostly centrally focused on the ideas of satisfaction and happiness, are determined unidimensionally, are less frequent in theory

- Dividing the construct of quality of life into multiple dimensions and domains, they are multidimensional

- The eclectic combinations of general and multidimensional definitions in which we find elements of both previous types.

If we divide the construct of quality of life into individual domains, then in the definition of the concept of quality of life in older people, we cannot avoid the dimensions: interpersonal relationships; social inclusion; personal development; physical wellbeing; self-determination; self-updating; material wellbeing; emotional wellbeing; legal guarantees; a possibility to use one's potential; etc.

At the same time, the levels of quality of life in older people can also be perceived from the vertical aspect. Quality of life in older people is influenced on various levels which include individual countries (the concept of quality of life varies in different countries), regions, cities, villages, urban areas, communities, external disadvantages, social surroundings, families, but also interests, activities (Gojova, 2006). Engel \& Bergsma (1988, in: Krivohlavy, 2002) organized the hierarchy of quality of life, i.e. quality of life in older people, in four levels:

- A macro level, life in large social units - country, self-governing region, place of residence, urban area, etc.

- A mezzo level, quality of life in small social groups - family, neighborly relations, friendship, social services facilities

- A personal level, personal life of an individual, mainly its subjective level

- A physical level, observable behavior of people that can be measured and compared

In our opinion, a clearer differentiation of levels of quality of life is by Schalock (2004), who divides the levels of quality of life into objective and subjective. According to him, the objective factors of quality of life are: social environment; social insurance; social policy; legislation; 
poverty rate; life expectancy; quality of health care; quality of social services; attitude of society towards older people; prejudices; exclusion of older people; discrimination of older people; etc. The subjective factors of quality of life include: feelings of security and safety; family relationships; relationships to social surroundings; health; hobbies; satisfaction; etc.

The relationships between the objective and subjective dimensions of quality of life were described by Svehlikova \& Heretik (2008). According to them, the result of the unity of the objective and subjective dimensions of quality of life are satisfaction and wellbeing of the older person; if there are the positive objective dimension and the negative subjective dimension the result is dissonance; if there are the negative objective dimension and the positive subjective dimension the result is adaptation; if both the objective and subjective dimensions are negative, the result is deprivation of the older person. The optimal combination includes the positive objective and subjective dimensions of quality of life.

Krivohlavy (2002) attempted to identify the methods of measuring quality of life and divided them into three groups:

- Methods of measuring quality of life through another person

- Methods of measuring quality of life by the person

- Mixed methods, which should be the most reliable

The studies on quality of life (Franz, Meyer et al. 2000), which may also be applied to the issue of older people, often find a high degree of overall life satisfaction despite neglected standards of living. According to the authors, social comparisons (as part of processes regulating satisfaction) play an important role in this phenomenon. Older people who lived in objectively problematic conditions compared themselves with older people whose conditions they subjectively perceived even more critically than their own. For example, an older person living in problematic conditions in his own apartment may tend to compare himself with an older person in a residential facility whose life situation he considers to be significantly worse (defense mechanisms work). A dilemma for a social worker in such a situation is whether to accept the decision of the older person to remain under threatening conditions or to motivate the older person to a radical change.

Another concept that closely communicates with the construct of quality of life and contributes to its complexity especially in the social area are social needs of older people. Needs can be understood as conditions whose fulfilment is necessary for the optimum state of the individual (in the systemic terminology it is the state of homeostasis) which is necessary for his full functioning. Baumeister \& Leary (1995, in: Heinrich, Gullon, 2006) distinguish between needs and wants. According to them, needs are intertwined with necessity while wants are associated with desire. Non-fulfilment of the basic needs leads to deprivation; non-fulfilment of wishes is accompanied by distress. In the context of quality of life and needs, we can accept the Bradshaw's (1972, in: Matousek, 2008) division of needs into: perceived needs which are subjectively experienced and often related to expectations (for example, „Counselling will not help me so I do not need it."); expressed needs are not only experienced but also communicated, the client expresses his need in the form of a request or demand; normative needs are part of the assessment of professionals in relation to a certain standard; comparative needs are based on the comparison of an individual (group) with another individual or a reference group. There are many theories of human needs but we have not found any consistent theory of social needs because it is difficult to clearly distinguish between social and psychological needs. For certain simplification and narrowing of the topic of social needs we defined social needs as interpersonal needs in the context of theories of attachment (Hasto 2005), social support network, social integration and perceived social support. For this reason the issues of altruism, care for someone, social security context, etc. are absent in the list above.

Holt \& Lundstad et al. (2010) identified three elements of social relations: the degree of integration into social networks; supportive social interactions (accepted social support); perceptions of the availability of support. The degree of integration is a structural aspect of social needs. In the context of older people, it includes marital status; status of living; relationships with family; quality of social networks; involvement in diverse social activities; identification with one's social role; re- 
lationship with a trustworthy person; a sense of solidarity; social isolation. The functional aspect is based on the availability of social relationships and includes acceptance of emotional, information and material support; fulfilment of the sense of belonging; availability of support, if needed; and the sense of isolation, non-involvement and disconnection. Social gains or losses can also be attributed to the functional aspects. The indicators of the problematic saturation of social needs of older people are their social isolation and feelings of loneliness, uselessness, failure, ultimately frustration and subsequent deprivation. Deprivation in older people leads to dysfunctional changes in somatic, psychological, spiritual and social areas.

In the paper, we attempted to point out the incoherence of the meaning and use of the construct of the concept of quality of life. When working with older people, it is essential to respect both objective and subjective aspects of quality of life. Objective quality of life includes objective standard of living of the older person; subjective quality expresses the subjective assessment of the objective conditions which may be influenced by social comparisons, aspirations, values, adaptation ability, etc. The combination of the domains of objective and subjective quality of life creates a more complex space for work with older people, such as a psychological approach which more strikingly prefers subjective quality of life (Dzuka, 2004). The construct of quality of life can be used in social work to know and understand life situation of older people; to formulate a common strategy for the planning of the older person and professional worker; and for a strategy for the use of specific activities which is based on the involvement of older people in and out of social facilities which creates space for higher quality of life. The important role of social workers is the motivation and involvement of older people in the creative influence of the social environment in which they live. Professionals working with older people have the same mission; they should not unilaterally focus on the counselling or therapeutic paradigms of social work, but more frequently they should use the reform paradigm aimed at improving the functioning of social systems from social policy and legislation to work in the field of social services to the use of community possibilities in favor of increasing quality of life in older people.
A significant and not frequent aspect of the issue of quality of life in older people is the proportional connection of quality of life in this target group and quality of life in social service providers. Poor living and working conditions of professionals significantly affect quality of life in their clients. Therefore, it is necessary to address the conditions and possibilities of quality of life comprehensively in the context of system theories.

\section{References:}

1. DZUKA J (2004) Psychological dimensions of life, quality of life - theoretical construct of quality of life - empirical findings. Presov, University of Presov, 2004. USBN 80-8068282-8.

2. FRANZ M et al. (2000) The importance of social comparisons for high levels of subjective quality of life in chronic schizophrenic patients. Quality of life research, vol. 9, no. 5, 2000.

3. GOJOVA A (2006) Theories and models of community work. Ostrava, University of Ostrava, 2006. ISBN 80-7368-154-4.

4. HASTO J (2005) Relationship. Trencin, Publisher F, 2005. ISBN 80-88952-28-X.

5. HEINRICH L, GULLONE E (2006) The clinical significance of loneliness: A literature review. Clinical psychol. rev., vol. 26, no. 6.

6. HOLT-LUNDSTAD J et al. (2010) Social relationships and mortality risk. A meta-analytic Review PLoS Med., vol.7, no 7.

7. KRIVOHLAVY J (2002) Psychology of the disease. Praha, Grada, 2002. ISBN 80-24701-79-0.

8. MATOUSEK O (2008) Dictionary of social work. Praha, Portal, 2008. ISBN 978-807367-368-0.

9. RAPLEY M (2003) Quality of life research. London, Sage Publications, 2003.

10. SCOTTISH EXECUTIVE SOCIAL RESEARCH (2005) Quality of Life and Wellbeing. Available:http://www.scotland.gov.uk/ Publications/2006/01/13110743/0

11. SCHALOCK, RL (2004) The concept of Quality of Life. Journal of Intellectual Disability Reaserch, vol.48, Pt.3.

12.SVEHLIKOVA L, HERETIK A (2008) Quality of life - what we are talking about? Psychiatry-Psychotherapy-Psychosomatics, vol. 15 , no. 3 . 